\title{
Research on the Occupational Noise Exposure Health Risk Management Standard
}

\author{
Minyan Li, Deyin Huang", Qian Zhang \\ Institute of Occupational Health, Tianjin Bohai Chemical Industry Group Co. Ltd, Tianjin 300051, China
}

Received September 21, 2018

Accepted October 19, 2018

\begin{abstract}
To prevent and control the occupational noise hazard, procedures and methods of risk assessment and management of occupational noise hazard in the workplaces have been proposed as technical guidelines in the new standard "Risk Management Guidelines for Noise Occupational Disease Hazard" based on the current status and technical requirements of occupational noise hazard in China. These guidelines are consist of the risk assessment method which partly adopts the method given by the latest ISO 1999:2013(E) "Acoustics - Estimation of noise induced hearing loss", and the risk management procedures which are mainly based on the US NIOSH's recommended standard "Occupational Noise Exposure Revised Criteria 1998". The guidelines put forward procedures and technical contents such as the risk management program, occupational noise exposure quantitative risk evaluation procedures and methods, and the implementation details of a hearing conservation plan. The standard is based on the current status and technical requirements of the occupational noise hazard in China, in accordance with the relevant national laws, regulations and standards related to hearing protection and supervision and management of the occupational hazard of construction projects. It can be used as guidelines for occupational noise exposure evaluation and risk assessment in various kinds of workplaces that produce productive noises and for exposure level monitoring, effectiveness evaluation of noise control measures, occupational health management, supervision and inspection.
\end{abstract}

Keywords: Noise; Hearing loss; Occupational Noise-induced Deafness; Risk Assessment; Risk Management

\section{Background}

It is well known that industrial noise exists extensively in many industrial fields. In the process of industrial production, almost all technological processes produce noises of different intensities. In some places the noise exposure levels even exceed the limits specified in national occupational health standard. As it has caused a high incidence of hearing loss, occupational noise-induced deafness has already included in the key occupational diseases list, in which occupational malignant tumor, occupational pneumoconiosis, occupational acute chemical poisoning are also included. Assessment and management guidelines for occupational health risk caused by most key hazards except noise had already been studied in China (Minyan Li et al., 2013, 2016; Qian Zhang et al., 2013, 2014) before this standard. The main problems in the prevention and control of noise occupational diseases could be summarized as: (1) The widely distributed occupational hazard noise, the large scale of noise occupational exposed population, and the high incidence of noise hearing loss; (2) Lack of standardized methods for noise exposure evaluation and quantitative hearing loss risk assessment; (3) Lack of standardized requirements for the hearing protection plan; (4) Lack of technical requirements for the implementation and supervision of the hearing protection plan; (5) Only baseline audiograms and monitoring audiograms were required, and the information recorded in medical surveillance files was incomplete; and (6) Risk management had not been the core of noise hazard prevention and control, and there were no technical requirements or specifications in China.

\footnotetext{
*Corresponding Author: huang_deyin@126.com
} 
Occupational noise deafness can be prevented, thus occupational noise exposure evaluation and risk assessment is one of the important methods for hearing protection management, the critical step of which is the quantitative risk assessment, which aims to put forward the feasible measures to prevent and control the noise hazard, guide the implementation of effective risk management and protect the health of the workers. An industry standard AQ/T 4276-2016 "Risk Management Guidelines for Noise Occupational Disease Hazard" was promulgated and implemented to change the occupational noise hazard status quo and meet the technical needs in China.

\section{Standardization Processes and References}

In the compilation process, the status quo and deficiencies of the occupational noise hazard management and evaluation of occupational hazard in construction projects in China had been mastered by studying literatures and collecting data, and opinions were preliminarily solicited. At the stage of soliciting opinions, it was formulated according with the procedures and requirements in GB/T 1.1-2009 and other standards. Opinions of the experts covered kinds of fields such as scientific research, industrial production, testing and inspection, training and supervision and inspection were extensively solicited. Furthermore, experts from related enterprises, technical service institutions, and supervisory and administrative departments were consulted in the form of a meeting in the review stage.

The main technical contents of occupational noise exposure quantitative risk assessment procedures and methods are based on ISO 1999:2013(E) "Acoustics - Estimation of noise induced hearing loss". The risk management procedures and guidelines of hearing protection plan are mainly developed based on the NIOSH document "CRITERIA FOR A RECOMMENDED STANDARD - Occupational Noise Exposure" Revised 1998 and our previous researches on risk assessment technology.

\section{Contents}

\subsection{Main contents}

This standard "Risk Management Guidelines for Noise Occupational Disease Hazard" puts forward procedures and technical contents such as the risk management program, occupational noise exposure quantitative risk evaluation procedures and methods, and the implementation details of a hearing conservation plan, giving an operational specification for evaluation of occupational noise hazard in construction projects and risk management of employers.

(1) Procedures and contents of occupational noise exposure risk assessment methods. The procedures and contents are as follows:

A) Investigation of occupational noise exposure: The characteristics of occupational exposure of workers shall be analyzed through the investigation of occupational noise exposure in the production process;

B) Evaluation of occupational noise exposure: Evaluation shall be carried out when the workers occupationally exposed to the noise of which the A-weighted sound level normalized to a nominal $8 \mathrm{~h}$ working day or $40 \mathrm{~h}$ working week(LEX,8h or LEX,W) is at or above $80 \mathrm{dBA}$;

C) Risk assessment of hearing loss caused by noise exposure: Quantitative risk assessment of hearing loss caused by noise exposure is conducted in accordance with the method prescribed by ISO 1999:2013;

D) Risk classification and management strategies of occupational noise hazard control: The risk of occupational noise hazard shall be classified according to the assessment results, and corresponding management strategies shall be guided to adopt.

(2) Procedures and contents for risk management of occupational noise hazard

According to the risk assessment results and proposed risk management guidelines for the prevention and control of hearing loss caused by occupational noise exposure, the risk management of the occupational noise hazard shall be implemented. Risk management procedures for occupational noise hazard are as follows:

A) Risk assessment of occupational noise hazard: The method of risk assessment shall conform to the provisions of the technical requirements of quantitative risk assessment;

B) Risk management and control of occupational noise hazard: Making a hearing protection plan, evaluating occupational noise exposure, engineering control and organization management measures, selection and use of hearing devices, occupational health surveillance, occupational hazards notification, training and archives management shall be included, and the effectiveness of the hearing protection plan shall be evaluated. 
(3) Normative and informative appendices

The normative appendices are additional provisions of the standard text which have the same effect as it, and the informative appendices give information to help understand or use the standard with the main contents as follows:

A) Risk assessment procedures for occupational noise hazard;

B) Survey on occupational noise exposure;

C) Risk assessment of hearing loss caused by noise exposure;

D) A risk assessment example;

E) Risk management principles;

F) Risk management procedures;

G) Guidelines for making a hearing protection plan;

H) Sheets of the hearing protection effectiveness evaluation.

\subsection{Technical requirements}

(1) To make up the lack of standardized methods of occupational noise exposure evaluation and quantitative risk assessment of hearing loss, the latest method in ISO 1999:2013(E) is used. Moreover, the risk assessment results could be used for management.

(2) The frame is given in the technical requirements in body text and normative appendices to meet the need of making a hearing protection plan.

(3) The risk classification method, risk management countermeasures of hearing loss caused by noise exposure and the management principles in appendices are given, filling the gap of technical requirements for the implementation of the hearing protection plan and its supervision.

(4) As the hearing test in occupational health surveillance usually requires only baseline audiogram and monitoring audiogram, and the changes of hearing loss caused by occupational noise exposure cannot be reflected completely or comprehensively, or analyzed dynamically using the data recorded in files, the technical requirements of retest audiogram and confirmation audiogram under specific conditions are given.

(5) For the calculation of hearing disability, a combination of hearing threshold levels at specified frequencies shall be used. The hearing threshold levels for the populations, their percentages, and exposure conditions of interest shall be calculated in accordance with Clause 6. A fence may be selected for the hearing threshold level above which a hearing disability is deemed to exist. The warning and alarm values of risk can be scientifically used for risk management, such as:

1) Evaluate the average noise-induced permanent threshold shift(NIPTS) and hearing threshold level associated with age and noise(HTLAN) for both ears at the high frequencies $(3000 \mathrm{~Hz} 、 4000 \mathrm{~Hz} 、 6000$ $\mathrm{Hz}$ ) with the fence $40 \mathrm{~dB}$ according to the preconditions for the diagnosis of occupational noise deafness specified in accordance with Clause 4 of GBZ 49-2014 and assess the risk of hearing loss for early warning;

2) Evaluate the weighted noise-induced permanent threshold shift(NIPTS) and hearing threshold level associated with age and noise(HTLAN) for better ear at the combination of speech frequencies $(500 \mathrm{~Hz}$ 、 $1000 \mathrm{~Hz} 、 2000 \mathrm{~Hz}$ ) and high frequency $(4000 \mathrm{~Hz})$, i.e. $1 / 3 \times[$ HL500 Hz+HL1000 Hz+HL2000 $\mathrm{Hz}] \times 0.9+\mathrm{HL} 4000 \mathrm{~Hz} \times 0.1$, with the fence $25 \mathrm{~dB}$, according to the classifications of the diagnosis of occupational noise deafness specified in accordance with Clause 4 of GBZ 49-2014 and assess the risk of hearing disability as an alarm.

\subsection{Explanations for technical requirements}

(1) The requirements in the section "4.2.3 risk assessment of hearing loss caused by noise exposure" and normative appendix $\mathrm{C}$ are not equivalent(NEQ) to that in the latest ISO 1999:2013(E) "Acoustics — Estimation of noise induced hearing loss". It is based on the later ISO standard compared with GB/T 14366-93 "Acoustic - Determination of occupational noise exposure and estimation of noise-induced hearing impairment" (eqv ISO 1999:1990).

It is mainly based on Clause 6 "prediction of the effects of noise on hearing threshold", Clause 7 "assessment of noise-induced hearing loss and disability", and the informative appendices A, B and D of ISO 1999:2013(E), giving an example as a supplement for the informative appendix $\mathrm{C}$ to calculate the risk based on formulas. Requirements in Clause 5" description and measurement of noise exposure" are not used in our standard because the method has been given in relevant standards in China. The example in the appendix $\mathrm{C}$ in ISO standard estimated the risk by looking up the given tables while appendix D of our AQ standard recommends to calculate by formulas based on Excel software instead, which is more precise and 
convenient to illustrate. As the relevant provisions about noise measurement have been specified in GBZ/T 189.8-2007, the national standard is adopted in Section 4.2.2 instead of the ISO method.

(2) Section 5.2 "Occupational noise hazard risk management ", normative appendices $F$ and $G$ are based on the US NIOSH's recommended standard "Occupational Noise Exposure Revised Criteria 1998".

It's based on the NIOSH recommendations about making a hearing protection plan, evaluating occupational noise exposure, engineering control and organization management measures, selection and use of hearing devices, occupational health surveillance, occupational hazards notification, and training and archives management, and considering the requirements of national laws, regulations, standards and specifications, and the actual noise hazard situation.

\section{Risk assessment method in the guidelines}

(1) The investigation on the noise occupational exposure situation includes production process, the fixed number of staff members of each workshop post and their tasks, the exposure situation of each post, the selection and use of hearing protectors, the draft and implement situation of hearing conservation program and occupational epidemiology data collection of similar enterprises in China, etc. According to the investigation results, the noise sources and workers affected could be identified to be used to analysis the occupational exposure characteristics.

(2) The instruments used the places to measure noise and the method to measure and calculate the sound levels all should be according to GBZ/T 189.8. A-weighted noise exposure level normalized to a nominal $8 \mathrm{~h}$ working day or nominal week of 5 eight-hour working days could be used to determine whether workers need to wear hearing protectors or not.

When the sound levels of the workplaces could not be measured, the occupational noise exposure levels could be forecast according to the measure data of similar enterprises in China and the past measure data of the workplaces of the employing unit itself.

(3) The potential risk of occupational noise-induced hearing loss could be quantitatively expressed by the noise-induced permanent threshold shift (NIPTS) and the percentages of a population whose hearing threshold level associated with age and noise (HTLAN) and hearing threshold level associated with age (HTLA) exceed the fence. To assess the risk of hearing loss and to estimate the hearing loss of hearing threshold level associated with age and noise and noise-induced permanent threshold shift is the manner to evaluate the affect that the noise induced in the occupational population. After selecting the appropriate frequency combinations and fences, percentages in the population whose HTLAN and HTLA of the selected frequency combinations which exceed the fences could be calculated, so that the NIPTS and the percentages of a population whose HTLAN and HTLA exceed the fence could be estimate.

The hearing threshold level, in decibels, associated with age and noise (HTLAN), H', of a noise-exposed population is calculated, for the purposes of this ISO model, by using Formula (1):

$$
H^{\prime}=H+N-\frac{H \times N}{120}
$$

where

$\mathrm{H}^{\prime}$ is the hearing threshold level, expressed in decibels, associated with age and noise (HTLAN);

$\mathrm{H}$ is the hearing threshold level, expressed in decibels, associated with age (HTLA);

$\mathrm{N}$ is the actual or potential noise-induced permanent threshold shift (NIPTS), expressed in decibels.

(4) A risk assessment case is given in Appendix $\mathrm{D}$ and the documentation notes give some detailed instructions with a calculating tool for users.

\section{A Case Study}

Choose workers from a battery assembly enterprise exposed to noise as objects whose risk of noise-induced hearing loss will be assessed. They are mostly males between 20 and 30 years old.

Based on the measurement results, the calculated average LEX, W of workers is $86.9 \mathrm{dBA}$.

Assuming that the male workers were exposed to the industrial noises without any personnel hearing protectors from 20 years old. Predict the HSTS and occupational noise deafness risks of population when they are 50,55 or 60 years old.

A Microsoft ${ }^{\circledR}$ Excel worksheet was compiled based on the method given before and the information above was input.

Choose database A to calculate the hearing threshold level associated with age, and use the compiled Excel worksheet to predict the HSTS and occupational noise deafness risk for these male workers if they do 
not wear any hearing protectors. The predicted risks of occupational noise deafness are given in Table 1 and the risk assessment results are expressed in Fig. 1, where

(1) Risk of hearing loss due to age and noise exposure, $13.0 \% \%$ (point $\mathrm{X}$ );

(2) Risk of hearing loss due to noise exposure, $2.9 \%$ (difference between point $\mathrm{X}$ and point $\mathrm{Y}$ );

(3) HTLA of noise-exposed population;

(4) NIPTS, $10 \%$;

(5 Assumed fence, $10 \mathrm{~dB}$;

(6) Non-noise-exposed population risk of hearing loss due to age, $10.1 \%$ (point $\mathrm{Y}$ );

(7) NIPTS, $50 \%$;

(8) HTLA of non-noise-exposed population;

(9) NIPTS, 90\%.

\section{Conclusions and Discussions}

AQ/T 4276-2016 "Risk Management Guidelines for Noise Occupational Disease Hazard" now have been issued and executed. It is based on the current status and technical requirements of the occupational noise hazard in China, in accordance with the relevant national laws, regulations and standards related to hearing protection and supervision and management of the occupational hazard of construction projects. The standard stipulates the procedures and methods of the risk assessment and management of occupational noise hazard, which provides guidelines for occupational noise exposure evaluation and risk assessment in various kinds of workplaces that produce productive noises and for monitoring, effectiveness evaluation of noise control measures, occupational health manage-

Table 1. Predicted risk of occupational noise deafness for the male workers in this workshop

\begin{tabular}{|c|c|c|c|c|c|c|c|c|c|c|c|c|c|}
\hline $\begin{array}{c}\text { Age } \\
\text { (years } \\
\text { ) }\end{array}$ & $\begin{array}{c}\text { Duration } \\
\text { (years) }\end{array}$ & $\begin{array}{c}H^{\prime}{ }_{10} \\
(\mathrm{~dB})\end{array}$ & $\begin{array}{c}H^{\prime}{ }_{50} \\
(\mathrm{~dB})\end{array}$ & $\begin{array}{c}H^{\prime}{ }^{\prime} \\
(\mathrm{dB})\end{array}$ & $\begin{array}{c}H_{10} \\
(\mathrm{~dB})\end{array}$ & $\begin{array}{c}H_{50} \\
(\mathrm{~dB})\end{array}$ & $\begin{array}{c}H_{90} \\
(\mathrm{~dB})\end{array}$ & $\begin{array}{c}N_{10} \\
(\mathrm{~dB})\end{array}$ & $\begin{array}{c}N_{50} \\
(\mathrm{~dB})\end{array}$ & $\begin{array}{c}N_{90} \\
(\mathrm{~dB})\end{array}$ & $\begin{array}{c}\text { Risk of } \\
\text { hearing } \\
\text { loss due } \\
\text { to age } \\
\text { and } \\
\text { noise } \\
\text { exposure } \\
(\%)\end{array}$ & $\begin{array}{c}\text { Non-noise- } \\
\text { exposed } \\
\text { population } \\
\text { risk of } \\
\text { hearing } \\
\text { loss due to } \\
\text { age }(\%)\end{array}$ & $\begin{array}{c}\text { Risk of } \\
\text { hearing } \\
\text { loss due } \\
\text { to age } \\
\text { and } \\
\text { noise } \\
\text { exposure } \\
(\%)\end{array}$ \\
\hline 50 & 30 & 20.0 & 7.6 & -2.4 & 18.1 & 6.1 & -3.5 & 1.9 & 1.5 & 1.1 & $0-5.0$ & $0-5.0$ & $0-5.0$ \\
\hline 55 & 35 & 23.2 & 9.6 & -1.2 & 21.3 & 8.1 & -2.4 & 1.8 & 1.5 & 1.2 & 7.3 & 5.1 & 2.2 \\
\hline
\end{tabular}



Fig.1. Assessment results of risk of occupational noise deafness for male workers of the workshop at the age of 60 . ment, supervision and inspection.

In conclusion, this standard for risk management of occupational noise hazard can fit in better in China than those foreign standards, and can meet more needs of domestic industrial enterprises, occupational health service agencies and management supervision department for risk management of occupational noise hazard.

In the future, feedbacks and opinions will be actively solicited and followed up for revision in order to make the risk management guidelines for occupational noise hazard more applicable and standardized.

\section{References}

[1] Minyan Li, Deyin Huang, Mao Liu M. MCSim-based occupational health risk assessment on benzene. Journal of Risk Analysis and Crisis Response, 2013, 3(3):135-145.

[2] Qian Zhang, Deyin Huang, Mao Liu. Internal exposure simulation based on exposure related dose estimating model. Journal of Risk Analysis and Crisis Response, 2013, 3(4):175-184. 
[3] Qian Zhang, Deyin Huang, Mao Liu. Study on risk evaluation based on occupational exposure evaluation and carcinogenic risk simulation. Journal of Risk Analysis and Crisis Response, 2014, 4(4):228-232.

[4] Minyan Li, Deyin Huang, Qian Zhang. Application of risk estimation of noise-induced hearing loss method in evaluations of occupational disease hazards in construction projects in China. Journal of Risk Analysis and Crisis Response, 2016, 6(2):76-84.

[5] GB/T 14366-93 Acoustics-Determination of occupational noise exposure and estimation of noise-induced hearing impairment (ISO 1999:1990,IDT)

[6] ISO 1999: 2013(E) Acoustics-Estimation of noise-induced hearing loss
[7] GBZ 49-2014 Diagnosis of occupational noise-induced deafness.

[8] GB/T 1.1-2009 Directives for standardization-Part1: Structure and drafting of standards.

[9] GBZ/T 189.8-2007 Measurement of Physical Agents in Workplace Part 8: Noise.

[10] U.S. Department of Health and Human Services, Public Health Service, Centers for Disease Control and Prevention, National Institute for Occupational Safety and Health. Criteria for a Recommended Standard-Occupational Noise Exposure[S/OL]. Cincinnati, Ohio: DHHS (NIOSH), 1998.

http://www.nonoise.org/hearing/criteria/criteria.htm. 